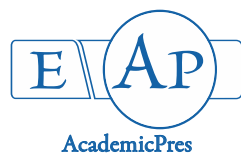

\title{
Hypoglycaemic and Hypolipidemic Effects of Black Brand of Lipton Tea (Camellia sinensis) on Normal Male Albino Rats
}

\author{
E.C. ANORUE ${ }^{1}$, E.C. MBEGBU ${ }^{2 *}$, G.I. NGWU ${ }^{1}$, K.N. IBEMENUGA ${ }^{3}$, \\ J.E. EYO ${ }^{1}$ \\ ${ }^{1}$ University of Nigeria, Department of Zoology and Environmental Biology, Nsukka, Enugu State, \\ Nigeria; edmund.mbegbu@unn.edu.ng (*corresponding author) \\ ${ }^{2}$ University of Nigeria, Department of Veterinary Physiology and Pharmacology, Nsukka, Enugu State, Nigeria \\ ${ }^{3}$ Anambra State University, Department of Biological Sciences, Uli, Anambra State, Nigeria
}

\begin{abstract}
Recently, considerable attention has been focused on dietary supplements that possess hypoglycaemic and hypolipidemic properties in lieu of the synergistically synthesized drugs like statins and metiform which have been proven to have adverse effects. This present work was carried out to study the potential effects of Lipton tea aqueous extract (LTAE) on normal male albino rats. 36 six male Wistar rats weighing 115 - 150g were assigned into four main groups; each group was divided into three subgroups, consisting of three replicates namely R1, R2 and R3 making a total of nine rats in each of the main groups. Group 1 served as the control and received only water, Group 2 received $200 \mathrm{mg} / \mathrm{kg}$ of LTAE, Group 3 received $400 \mathrm{mg} / \mathrm{kg}$ of the LTAE, while Group 4 received $800 \mathrm{mg} / \mathrm{kg}$ of LTAE. All treatment was given orally on daily basis for 28 consecutive days, but the parameters were assessed on weekly basis. The result revealed that, weight gain, fasting blood sugar and serum (total cholesterol, triglycerides, LDL-c and VLDL-c) significantly $(\mathrm{p}<0.05)$ decrease in all the treated groups while HDL-c significantly $(\mathrm{p}<0.05)$ increased when compared to the control group. The Lipton tea aqueous extract induced both a dosedependent and a time-dependent effect in the parameters measured, apart from the total cholesterol which did not show a dose-dependent effect. This led to an overall decrease in the antherogenic index and coronary risk index, suggesting that LTAE possesses hypoglycaemic and hypoglycaemic activities in normal male rats.
\end{abstract}

Keywords: antherogenic index; Camellia sinensis; coronary risk index; hypoglycaemia; rats

\section{Introduction}

Diabetes mellitus $(\mathrm{DM})$ is the term used to refer to impairment in insulin metabolism (Aizaki et al., 1999). Despite major investigations into understanding the pathophysiology and treatment of diabetes mellitus, it has remained a major health problem worldwide (Baynes and Thorpe, 1999). The total number of people with diabetes is projected to rise from 171 million in 2000 to 366 million in 2030 (Broadhurst et al., 2000). The national diabetes information clearing house of the United States of America estimates that diabetes costs $\$ 132$ billion in the United States alone every year, and that one in three Americans born after year 2000 may develop diabetes in their lifetime (Broadhurst et al., 2000).

There are several forms of diabetes mellitus but of all the forms, type 1 and type 2 are the major forms of diabetes mellitus and is the leading cause of abnormalities in the metabolism of carbohydrates and lipids in the body (Allain et al., 1974; Eyo et al., 2011). Lipid and carbohydrates are important metabolites in the body and abnormalities in their metabolism can lead to development and progression of many diseases and eventually mortality if not properly treated (Al Jamal, 2014). The abnormality in the regulation of these metabolites in the body leads to increase in their amount in the body, a condition referred to as hyperglycaemia and hyperlipidemia, leading to multifarious group of chronic disorders and morbidity in the body (Willett et al., 2002; Abe et al., 2005). Ahmed (2005) opined that several chronic diseases have been associated with an increased level of glucose and lipid in the body.

DM equally may be due to abnormalities in lipid metabolism, such as elevated circulating levels of triglycerides (TG), total cholesterol (TC), low density lipoprotein cholesterol (LDL-c), very low density lipoprotein cholesterol (VLDL-c) and usually accompanied by decreased circulating levels of high density lipoprotein cholesterol (HDL-c) (Murray et al., 2014). These can lead to other complications such as obesity, heart attack, stroke, 
hypertension and other related cardiovascular diseases (Cameron et al., 2008).

Insulin is a key hormone in the regulation of carbohydrates, lipids and protein metabolism in the liver (Ahmad et al., 1997). It is a hormone produced by the $\beta$ cells of islet of Langerhans in the pancreas, an organ located behind the stomach (Nelson et al., 2008). Type 1 diabetes is also known as insulin deficiency, while type 2 is known as insulin resistance (King et al., 1998). Based on the current understanding of pathophysiology of insulin resistance and insulin deficiency, multiple pharmacological and nonpharmacological interventions have been developed with the aim of improving both gylcemic and lipidemic control and prevention of diabetes complications.

Recently, the use of functional foods and their bioactive components have been considered as a new approach in the prevention and management of diabetes and its complications (Ozougwu et al., 2008; Ozougwu and Eyo, 2010; 2011). Thus this has been an ever increasing area of research for scientist so as to find out diets that will help alleviate the skyrocketing effects of diabetes mellitus and other diseases in the society, especially in the face of the fact that efficacy and safety of known synthetic drugs are dwindling (Ezuruike and Prieto, 2014).

Camellia sinensis is a species of evergreen shrub whose leaves and leaf buds are used to produce tea ( $\mathrm{Li}$ et al., 2013). It is of flowering plants genus Camellia in the family Theaceae ( $\mathrm{Li}$ et al., 2013). Lipton tea (Camellia sinensis) is one of such dietary component of plant origin with folklore claim of lowering blood sugar and body fats among other health benefits. It has also been reported to possess anticarcinogenic, anti-inflammatory, anti-mutagenic and antioxidative activities (Hasanein et al., 2012). Generally the health benefits associated with black brand of Lipton tea (yellow label) are believed to be due to presence of high level of polyphenols as well as flavonoids (Hasanein et al., 2012). These phytochemicals have the reputation of lowering the blood sugar and fatty acids (Dulloo et al., 2000).

The present study therefore was designed to determine the hypoglycaemic and hypolipidaemic effects of Lipton tea, with respect to body weight, fasting blood sugar concentration, lipid profile, antherogenic index and coronary risk index of normal male albino rats.

\section{Materials and Methods}

\section{Procurement of Lipton tea and extraction}

Lipton yellow label tea, Unilever (Camellia sinensis) was purchased from Ogige market, Nsukka, Nigeria. Aqueous extract of the Lipton tea on daily basis was gotten by extracting 8 Lipton tea bags in $100 \mathrm{ml}$ of hot distilled water. The aqueous extract was evaporated to dryness in a rotary evaporator (Stuart, model RE-300, UK). Concentration was determined thus:

Extract concentration $(\mathrm{mg} / \mathrm{ml})=\left(\mathrm{W}_{2}-\mathrm{W}_{1}\right) / 100$

Where: W1 $(\mathrm{mg})=$ Weight of beaker and W2 $(\mathrm{mg})=$ Weight of beaker $+100 \mathrm{ml}$ of extract evaporated to dryness.

\section{Animals}

Thirty six (36) healthy male albino Wistar rats (Rattus norvegicus) weighing 115 - $150 \mathrm{~g}$ were used for the study. They were purchased from the animal house of the Department of Zoology and Environmental Biology, University of Nigeria, Nsukka. They were housed in clean and dry metal cages under 12 hours conditions of light, temperature $(24 \pm 2)$ and relative humidity $(55 \pm 5 \%)$. The animals were fed standard rat chow made up of $15 \%$ crude protein, and water ad libitum. Before sampling, the animals were fasted overnight but allowed free access to water. The ethical committee of the university approved the study protocol prior to commencement of the study. The study was carried out in accordance with the guidelines for ethical conduct in the care and use of nonhuman animals in research (APA 2012).

\section{Experimental design}

The experimental setup was done using completely randomized block design. A total of thirty six rats were used for the study. The rats were randomly assigned into four (4) experimental groups (one control and three treatments). Each group was further divided into three replicates of 3 rats each. Group one served as control and received only distilled water, groups 2 - 4 received graded doses (200, 400 and 800 $\mathrm{mg} / \mathrm{kg}$ respectively) of LTAE. All treatments were given on daily basis for 28 consecutive days. The body weight, lipid profile and the glucose level were monitored weekly for 4 weeks of experimentation.

\section{Measurement of body weight}

Body weights of the rats were measured weekly using electronic top loading balance (Mettler Toledo Series) to the nearest $0.01 \mathrm{~g}$. The body weight gain and loose in grams was determined using the formulae; final weight - initial weight.

\section{Blood collection and determination of fasting blood sugar}

Blood samples for fasting blood sugar $(\mathrm{mg} / \mathrm{dl})$ were collected through the tail vein dripped directly into Accu Chek glucometer (Trinder, 1969). Blood samples for lipid profile were collected from the rats via the retrobulbar plexus at the median canthus of the eye (Parasuraman et al., 2010), allowed to clot inside test tube and centrifuged at $10,000 \mathrm{rpm}$ for 5 minutes; the supernatant (serum) was separated and poured into another test tube. The lipid profile was later measured using the serum.

\section{Determination of total cholesterol concentration}

The total cholesterol was determined after enzymatic hydrolysis and oxidation, according to the method described by Richmond (1973) using the Randox Kit for total cholesterol (Randox Laboratories Limited, London). One ml cholesterol reagent (R1) was put into two test tubes, labelled test and standard. Serum sample and standard cholesterol (10 $\mu \mathrm{l}$ respectively) was added into the appropriate test tube, well mixed and incubated at room temperature for 10 minutes. Absorbencies were taken using a colorimeter, set at $500 \mathrm{~nm}$.

The concentration of cholesterol $(\mathrm{mmol} / \mathrm{l})=$

(Absorbance of standard $\times$ Concentration of standard)/Absorbance of test samples 
96

Determination of triglyceride (TG)

The triglyceride was determined after enzymatic hydrolysis with lipases according to the method described by Fossati and Prencipe (1982) is using the Randox Kit for triglyceride (Randox Laboratories limited, London). One $\mathrm{ml}$ triglyceride reagent (R1) was pipette into test tube, labelled test and standard. Serum sample and standard triglyceride (10 $\mu \mathrm{l}$ respectively) was added into the appropriate test tubes. It was mixed and incubated at room temperature for 10 minutes. Absorbances were taken using a calorimeter, set at $500 \mathrm{~nm}$.

The concentration of triglyceride $(\mathrm{mmol} / \mathrm{l})=$

(Absorbance of standard $\times$ Concentration of standard)/Absorbance of test samples.

Determination of high density lipoprotein cholesterol (HDL-c)

The high density lipoprotein cholesterol was determined after using $\mathrm{MgCl}_{2}$ and dextran sulfate to precipitate all low-density and very-low-density lipoproteins according to the method described by Finley et al. (1978) using the Randox Kit for high density lipoprotein cholesterol (Randox Laboratories Limited, London). $20 \mu \mathrm{l}$ of serum was pipette into two test tube, labelled test and standard. Diluted precipitate (R1) $(500 \mu 1)$ was added into the appropriate test tubes. It was mixed and incubated at room temperature for 10 minutes. It was centrifuged for 10 minutes at $4000 \mathrm{rpm}$. The clear supernatant was put into other test tubes. Then $1 \mathrm{ml}$ cholesterol reagent (R1) was put into test tubes, labelled test and standard. Serum sample and standard cholesterol (10 $\mu 1$ respectively) was added into the appropriate test tube. It was mixed and incubated at room temperature for 10 minutes. Absorbencies were taken using a colorimeter, set at $500 \mathrm{~nm}$.

The concentration of HDL-cholesterol $(\mathrm{mmol} / \mathrm{l})=$

(Absorbance of standard $\times$ Concentration of standard)/Absorbance of test samples

Determination of very low density lipoprotein-cholesterol (VLDL-c)

The very low density lipoprotein-cholesterol (VLDL-c) can be determined using the formula: VLDL-cholesterol $(\mathrm{mmol} / \mathrm{l})=$ Triglyceride $\div 5$ according to Friedewald $e t$ al . (1972).

Determination of low density lipoprotein-cholesterol $(L D L-c)$

The low density lipoprotein-cholesterol (LDL-c) was determined using the formula below:

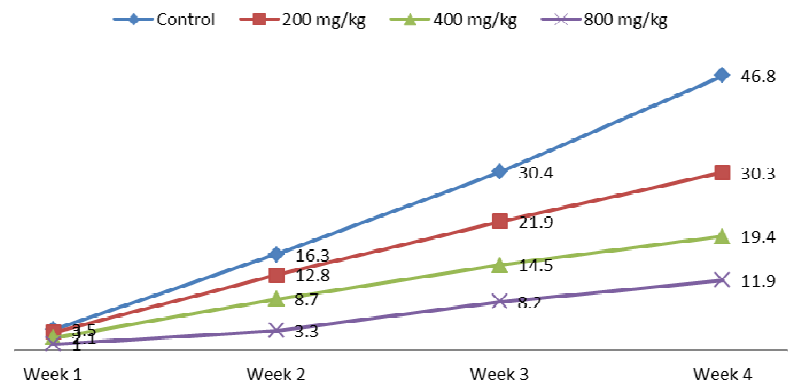

Fig. 1. Effect of Lipton tea aqueous extract on body weight gain of normal albino rat
LDL-cholesterol $(\mathrm{mmol} / \mathrm{l}))=$ Total cholesterol (HDL-c + VLDL-c), according to Friedewald et al. (1972).

Determination of atherogenic index (AI)

Atherogenic index (AI) was calculated using the equation described by Adeneye and Olagunju (2009):

$\mathrm{AI}=\mathrm{LDL}$-cholesterol/HDL-cholesterol.

Determination of coronary risk index (CRI)

Coronary Risk Index (CRI) was calculated using the equation described by Adeneye and Olagunju (2009):

$\mathrm{CRI}=$ Total cholesterol/HDL-cholesterol.

Statistical analysis

Data obtained were analyzed using analysis of variance by employing the Statistical Package for the Social Sciences (SPSS version 18 for windows). Differences between means were separated using Duncan's Multiple Range Test (Duncan 1955). Statistical significance was set at $\mathrm{p}<0.05$. Results were reported as mean \pm SEM.

\section{Results}

Concentration of the Lipton extract

The concentration of the extract was calculated as $=40$ $\mathrm{mg} / \mathrm{ml}$.

Effect of Lipton tea aqueous extract on body weight gain (g) of normal albino rat

The result of the effect of LTAE on body weight gain showed that all treatments significantly $(p<0.05)$ precipitated dose-dependent decrease and time-dependent increase in body weight gain of the treated rats from week 1 to week 4 when compared to the control (Fig. 1).

Effect of Lipton tea aqueous extract on fasting blood sugar ( $\mathrm{mg} / \mathrm{dl}$ ) of normal albino rats

The result of the effect of LTAE on fasting blood sugar level of normal albino rats showed that the extract significantly $(p<0.05)$ decreased the fasting blood sugar of the treated rats in both time dependent and dose dependent manner. The group treated with $800 \mathrm{mg} / \mathrm{kg}$ had the highest reduction in fasting blood sugar when compared to the 400 and $200 \mathrm{mg} / \mathrm{kg}$ doses except for week 2 and week 3 . Equally, the median and low doses of the LTAE significantly $(\mathrm{p}<$ 0.05 ) reduced the fasting blood sugar when compared to the control. Generally, all the doses of the extract precipitated significant $(\mathrm{p}<0.05)$ reduction in the fasting blood sugar (Fig. 2).

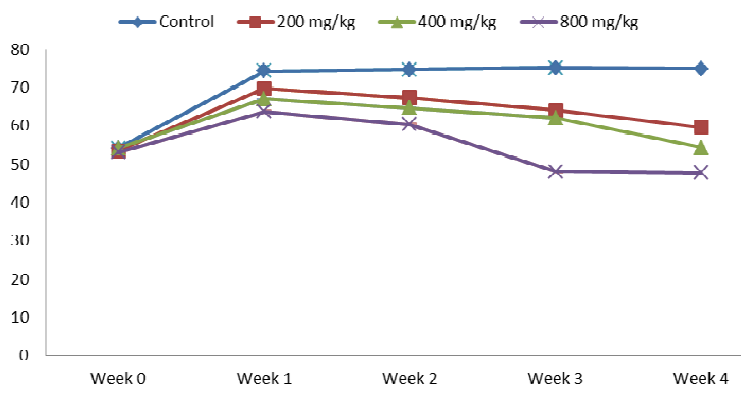

Fig. 2. Effect of Lipton tea aqueous extract on fasting blood sugar $(\mathrm{mg} / \mathrm{dl})$ of normal albino rats 
Effect of Lipton tea aqueous extract on total cholesterol (mmol/l) of normal albino rats

The result of the effect of LTAE on total cholesterol level showed that the extract caused a time- dependent decrease in total cholesterol level as from week 2 of the experiment. However, the different doses of the Lipton tea aqueous extract used in this study significantly $(\mathrm{p}<0.05)$ reduced the total cholesterol level from week 2 to week 4 when compared to the control. There is no significant $(\mathrm{p}>$ 0.05 ) difference among the treated doses except for the group treated with $800 \mathrm{mg} / \mathrm{kg}$ at week 3 where total cholesterol level was significantly $(\mathrm{p}<0.05)$ lower than that of other treatment groups. The total cholesterol level of the control group increased significantly $(p<0.05)$ throughout the period of the experiment (Table 1$)$.

Effect of Lipton tea aqueous extract on triglycerides (mmol/l) of normal albino rats

The result of LTAE on triglycerides showed that all the doses of the extract significantly $(p<0.05)$ decreased the serum triglycerides from week 3 of the experiment when compared to the control group. However, LTAE generally decreased $(p<0.05)$ the triglycerides in a time-dependent manner from week 3 of the experiment (Table 2).

Effect of Lipton tea aqueous extract on $H D L_{-C}(m m o l / l)$ of normal albino rats

The result of the effect of LTAE on high density lipoprotein cholesterol showed that the extract significantly $(\mathrm{p}<0.05)$ increased the high density lipoprotein cholesterol of the treated rats in both time-dependent and dosedependent manner when compared to the control. The extract at the highest dose $(800 \mathrm{mg} / \mathrm{kg})$ by week 4 gave the highest high density lipoprotein cholesterol value of 2.40 $\mathrm{mmol} / \mathrm{l}$ (Table 3).

Effect of Lipton tea aqueous extract on $L D L{ }_{-C}(\mathrm{mmol} / \mathrm{l})$ of normal albino rats

The result of the effect of LTAE on low density lipoprotein cholesterol showed that the extract significantly $(\mathrm{p}<0.05)$ reduced the low density lipoprotein cholesterol value of the treated rats in both time-dependent and dosedependent manner when compared to the control. The LTAE at the highest dose $(800 \mathrm{mg} / \mathrm{kg})$ by week 4 gave the lowest low density lipoprotein cholesterol $(0.76 \mathrm{mmol} / \mathrm{l})$ (Table 4).

Table 1. Effect of Lipton tea aqueous extract on total cholesterol ( $\mathrm{mmol} / \mathrm{l})$ of normal albino rats

\begin{tabular}{cccccc}
\hline \multirow{2}{*}{ Dose $(\mathrm{mg} / \mathrm{kg})$} & \multicolumn{5}{c}{ Duration (Weeks) } \\
\cline { 2 - 6 } & 0 & 1 & 2 & 3 & 4 \\
\hline $0.00($ Control $)$ & $4.2 \pm 0.06^{\text {al }}$ & $4.8 \pm 0.12^{\mathrm{bl}}$ & $4.9 \pm 0.19^{\mathrm{bcl}}$ & $5.0 \pm 0.17^{\mathrm{bcl}}$ & $5.2 \pm 0.23^{\mathrm{cl}}$ \\
200 & $4.1 \pm 0.06^{\mathrm{al}}$ & $4.7 \pm 0.17^{\mathrm{b1}}$ & $4.6 \pm 0.27^{\mathrm{b} 12}$ & $4.2 \pm 0.17^{\mathrm{ab} 2}$ & $3.5 \pm 0.17^{\mathrm{c} 2}$ \\
400 & $4.2 \pm 0.12^{\mathrm{al}}$ & $4.6 \pm 0.12^{\mathrm{bl}}$ & $4.5 \pm 0.15^{\mathrm{b} 2}$ & $4.0 \pm 0.23^{\mathrm{a2}}$ & $3.4 \pm 0.17^{\mathrm{c} 2}$ \\
800 & $4.2 \pm 0.06^{\mathrm{al}}$ & $4.8 \pm 0.60^{\mathrm{al}}$ & $4.4 \pm 0.18^{\mathrm{a} 2}$ & $3.4 \pm 0.19^{\mathrm{b3}}$ & $3.3 \pm 0.15^{\mathrm{b} 2}$ \\
\hline
\end{tabular}

Mean values with different numbers as superscripts in a column are significant $(\mathrm{p} \leq 0.05)$. Mean values with different alphabets as superscripts in a row are significant ( $\mathrm{p}$ $\leq 0.05)$.

Table 2. Effect of Lipton tea aqueous extract on triglycerides of normal albino rats

\begin{tabular}{|c|c|c|c|c|c|}
\hline \multirow{2}{*}{ Dose $(\mathrm{mg} / \mathrm{kg})$} & \multicolumn{5}{|c|}{ Duration (Weeks) } \\
\hline & 0 & 1 & 2 & 3 & 4 \\
\hline 0.00 (Control) & $1.77 \pm 0.03^{\mathrm{al}}$ & $1.70 \pm 0.12^{\mathrm{abl}}$ & $1.60 \pm 0.12^{b 1}$ & $1.70 \pm 0.12^{\mathrm{abl}}$ & $1.60 \pm 0.12^{b 1}$ \\
\hline 200 & $1.76 \pm 0.03^{\mathrm{a} 1}$ & $1.60 \pm 0.12^{\mathrm{al}}$ & $1.50 \pm 0.06^{\text {bc12 }}$ & $1.40 \pm 0.06^{c 2}$ & $1.30 \pm 0.17^{\mathrm{c} 2}$ \\
\hline 400 & $1.63 \pm 0.15^{\mathrm{a} 1}$ & $1.70 \pm 0.12^{\mathrm{a} 1}$ & $1.40 \pm 0.06^{\mathrm{b} 2}$ & $1.20 \pm 0.06^{\mathrm{c} 3}$ & $0.90 \pm 0.06^{\mathrm{d} 3}$ \\
\hline 800 & $1.70 \pm 0.10^{\mathrm{al}}$ & $1.60 \pm 0.12^{\mathrm{al}}$ & $1.30 \pm 0.17 \mathrm{~b} 2$ & $1.00 \pm 0.12^{c 4}$ & $0.73 \pm 0.15^{c 3}$ \\
\hline
\end{tabular}

Mean values with different numbers as superscripts in a column are significant $(\mathrm{p} \leq 0.05)$. Mean values with different alphabets as superscripts in a row are significant $(\mathrm{p}$ $\leq 0.05)$.

Table 3. Effect of Lipton tea aqueous extract on HDL-C ( $\mathrm{mmol} / \mathrm{l})$ of normal albino rats

\begin{tabular}{|c|c|c|c|c|c|}
\hline \multirow{2}{*}{ Dose $(\mathrm{mg} / \mathrm{kg})$} & \multicolumn{5}{|c|}{ Duration (Weeks) } \\
\hline & 0 & 1 & 2 & 3 & 4 \\
\hline $0.00($ Control $)$ & $0.80 \pm 0.12^{a 1}$ & $1.30 \pm 0.17^{b l}$ & $1.20 \pm 0.06^{\mathrm{bl}}$ & $1.00 \pm 0.06^{\mathrm{cl}}$ & $0.80 \pm 0.06^{a 1}$ \\
\hline 200 & $0.93 \pm 0.15^{\mathrm{a} 1}$ & $1.40 \pm 0.06^{\mathrm{bl}}$ & $1.53 \pm 0.15^{b c 2}$ & $1.70 \pm 0.12^{\mathrm{c} 2}$ & $1.90 \pm 0.06^{\mathrm{d} 2}$ \\
\hline 400 & $1.00 \pm 0.17^{\mathrm{a} 1}$ & $1.50 \pm 0.12^{\mathrm{b} 12}$ & $1.60 \pm 0.17^{b c 2}$ & $1.80 \pm 0.12^{\mathrm{c} 2}$ & $2.10 \pm 0.12^{\mathrm{d} 3}$ \\
\hline 800 & $1.00 \pm 0.12^{\mathrm{a} 1}$ & $1.60 \pm 12^{\mathrm{b} 2}$ & $1.70 \pm 0.12^{\mathrm{b} 2}$ & $2.10 \pm 0.60^{\mathrm{c} 3}$ & $2.40 \pm 0.21^{\mathrm{d} 3}$ \\
\hline
\end{tabular}

Mean values with different numbers as superscripts in a column are significant ( $\mathrm{p} \leq 0.05)$. Mean values with different alphabets as superscripts in a row are significant ( $\mathrm{p}$ $\leq 0.05)$.

Table 4. Effect of Lipton tea aqueous extract on LDL-C ( $\mathrm{mmol} / \mathrm{l})$ of normal albino rats

\begin{tabular}{|c|c|c|c|c|c|}
\hline \multirow{2}{*}{ Dose $(\mathrm{mg} / \mathrm{kg})$} & \multicolumn{5}{|c|}{ Duration (Weeks) } \\
\hline & 0 & 1 & 2 & 3 & 4 \\
\hline 0.00 (Control) & $3.06 \pm 0.01^{\mathrm{al}}$ & $2.90 \pm 0.04^{\mathrm{bl}}$ & $2.88 \pm 0.01^{b l}$ & $2.90 \pm 0.01^{b l}$ & $2.88 \pm 0.01^{b l}$ \\
\hline 200 & $3.04 \pm 0.01^{\mathrm{al}}$ & $2.83 \pm 0.10^{\mathrm{b} 12}$ & $2.70 \pm 0.06^{\mathrm{b} 2}$ & $2.22 \pm 0.01^{\mathrm{c} 2}$ & $1.34 \pm 0.01^{\mathrm{d} 2}$ \\
\hline 400 & $3.06 \pm 0.01^{\mathrm{al}}$ & $2.76 \pm 0.01^{b 2}$ & $2.62 \pm 0.01^{c 3}$ & $1.96 \pm 0.01^{\mathrm{d} 3}$ & $1.12 \pm 0.01^{\mathrm{e} 3}$ \\
\hline 800 & $3.05 \pm 0.02^{\mathrm{a} 1}$ & $2.58 \pm 0.01^{\mathrm{b} 3}$ & $2.44 \pm 0.02^{\mathrm{c} 4}$ & $1.60 \pm 0.02^{\mathrm{d} 4}$ & $0.76 \pm 0.02^{\mathrm{e} 4}$ \\
\hline
\end{tabular}

Mean values with different numbers as superscripts in a column are significant $(\mathrm{p} \leq 0.05)$. Mean values with different alphabets as superscripts in a row are significant $(\mathrm{p}$ $\leq 0.05)$. 
98

Effect of Lipton tea aqueous extract on $V L D L-_{C}(m m o l / l)$ of normal albino rats

The result of the effect of LTAE on very low density lipoprotein cholesterol showed that the extract significantly $(\mathrm{p}<0.05)$ reduced the very low density lipoprotein cholesterol value of the treated rats in both time-dependent and dose-dependent manner from week 2 to week 4 of the experiment. As a result the highest dose of the extract by week 4 gave the lowest value of $0.14 \mathrm{mmol} / \mathrm{l}$ (Table 5 ).

Effect of Lipton tea aqueous extract on atherogenic index (mmol/l) of normal albino rats

The result of the effect of LTAE on atherogenic index showed that the extract significantly $(p<0.05)$ reduced the atherogenic index of the treated groups in both timedependent and dose-dependent manner when compared to the control. The LTAE at the highest dose of $800 \mathrm{mg} / \mathrm{kg}$ by week 4 gave the lowest atherogenic index of $0.28 \mathrm{mmol} / \mathrm{l}$ (Table 6).

Effect of Lipton tea aqueous extract on coronary risk index (mmol/l) of normal albino rats

The result of the effect of LTAE on coronary risk index showed that the extract significantly $(p<0.05)$ reduced the coronary risk index of the treated rats in both timedependent and dose-dependent manner when compared to the control.
The LTAE at the highest dose of $800 \mathrm{mg} / \mathrm{kg}$ by week 4 gave the lowest coronary risk index of $1.38 \mathrm{mmol} / \mathrm{l}$ (Table 7).

\section{Discussion}

In the present study, treatment with Lipton tea aqueous extract (LTAE) on normal albino rats produced significant decrease in weight gain of the treated groups with the group treated with the highest dose of LTAE having the highest decrease, followed by the group treated with the median dose and finally the group treated with the lowest dose having the lowest decrease.

All treated group with different doses of LTAE showed significant decrease in final weight gain as compared to the control group. This could be due to decrease in feed intake observed throughout the period of the experimentation. Wang et al. (2006) opined that the decrease in feed intake could be due to the presence of caffeine in LTAE which reduces the level of serum leptin and decreased their appetite for food which in turn had significant reductive effect on weight gain. It could also be due to the presence of catechins and caffeine which are effective promoters of thermogenesis which invariably impacts on the hypothalamus, and fat oxidation, resulting in reduction in body weight gain (Khan and Mukhtar, 2013; Yashin et al., 2013).

Table 5. Effect of Lipton tea aqueous extract on VLDL-c ( $\mathrm{mmol} / \mathrm{l})$ of normal albino rats

\begin{tabular}{|c|c|c|c|c|c|}
\hline \multirow{2}{*}{ Dose $(\mathrm{mg} / \mathrm{kg})$} & \multicolumn{5}{|c|}{ Duration (Weeks) } \\
\hline & 0 & 1 & 2 & 3 & 4 \\
\hline 0.00 (Control) & $0.34 \pm 0.01^{\text {al }}$ & $0.34 \pm 0.01^{\text {aI }}$ & $0.32 \pm 0.02^{\text {al }}$ & $0.34 \pm 0.01^{\text {al }}$ & $0.34 \pm 0.01^{\text {al }}$ \\
\hline 200 & $0.36 \pm 0.02^{\mathrm{a} 1}$ & $0.34 \pm 0.01^{\mathrm{al}}$ & $0.30 \pm 0.01^{b 1}$ & $0.28 \pm 0.01^{b c 2}$ & $0.26 \pm 0.01^{c 2}$ \\
\hline 400 & $0.34 \pm 0.01^{\mathrm{al}}$ & $0.32 \pm 0.02^{\mathrm{a} 1}$ & $0.28 \pm 0.12^{\mathrm{b} 12}$ & $0.24 \pm 0.01^{\mathrm{c} 3}$ & $0.18 \pm 0.02^{\mathrm{d} 3}$ \\
\hline 800 & $0.32 \pm 0.02^{\mathrm{al}}$ & $0.32 \pm 0.02^{\mathrm{al}}$ & $0.26 \pm 0.01^{\mathrm{b} 2}$ & $0.20 \pm 0.01^{\mathrm{c} 4}$ & $0.14 \pm 0.02^{\mathrm{d} 3}$ \\
\hline
\end{tabular}

Mean values with different numbers as superscripts in a column are significant $(\mathrm{p} \leq 0.05)$. Mean values with different alphabets as superscripts in a row are significant $(\mathrm{p}$ $\leq 0.05)$.

Table 6. Effect of Lipton tea aqueous extract on atherogenic index $(\mathrm{mmol} / \mathrm{l})$ of normal albino rats

\begin{tabular}{|c|c|c|c|c|c|}
\hline \multirow{2}{*}{ Dose $(\mathrm{mg} / \mathrm{kg})$} & \multicolumn{5}{|c|}{ Duration (Weeks) } \\
\hline & 0 & 1 & 2 & 3 & 4 \\
\hline 0.00 (Control) & $3.16 \pm 0.01^{\text {al }}$ & $3.16 \pm 0.01^{\mathrm{al}}$ & $3.16 \pm 0.02^{\mathrm{abl}}$ & $3.17 \pm 0.09^{\mathrm{ab} 1}$ & $3.21 \pm 0.03^{b 1}$ \\
\hline 200 & $3.16 \pm 0.01^{\mathrm{al}}$ & $2.13 \pm 0.02^{\mathrm{b} 2}$ & $1.89 \pm 0.01^{\mathrm{c} 2}$ & $1.31 \pm 0.01^{\mathrm{d} 2}$ & $0.71 \pm 0.01^{\mathrm{e} 2}$ \\
\hline 400 & $3.18 \pm 0.01^{\mathrm{al}}$ & $1.84 \pm 0.01^{\mathrm{b} 3}$ & $1.64 \pm 0.02^{\mathrm{c} 3}$ & $1.09 \pm 0.02^{\mathrm{d} 3}$ & $0.53 \pm 0.02^{\mathrm{e} 3}$ \\
\hline 800 & $3.17 \pm 0.01^{\mathrm{al}}$ & $1.61 \pm 0.01^{\mathrm{b} 4}$ & $1.44 \pm 0.01^{\mathrm{c} 4}$ & $0.76 \pm 0.01^{\mathrm{d} 4}$ & $0.28 \pm 0.01^{\mathrm{e} 4}$ \\
\hline
\end{tabular}
$\leq 0.05)$.

Table 7. Effect of Lipton tea aqueous extract on coronary risk index $(\mathrm{mmol} / \mathrm{l})$ of normal albino rats

\begin{tabular}{|c|c|c|c|c|c|}
\hline \multirow{2}{*}{ Dose $(\mathrm{mg} / \mathrm{kg})$} & \multicolumn{5}{|c|}{ Duration (Weeks) } \\
\hline & 0 & 1 & 2 & 3 & 4 \\
\hline 0.00 (Control) & $3.69 \pm 0.09^{a 1}$ & $3.69 \pm 0.01^{\text {al }}$ & $3.69 \pm 0.03^{\mathrm{abl}}$ & $3.69 \pm 0.01^{\text {al }}$ & $3.53 \pm 0.09^{b l}$ \\
\hline 200 & $3.65 \pm 0.03^{\mathrm{a} l}$ & $3.36 \pm 0.01^{b 2}$ & $3.07 \pm 0.02^{c 2}$ & $2.47 \pm 0.01^{\mathrm{d} 2}$ & $1.84 \pm 0.02^{\mathrm{e} 2}$ \\
\hline 400 & $3.69 \pm 0.08^{\mathrm{al}}$ & $3.07 \pm 0.01^{\mathrm{b} 2}$ & $2.81 \pm 0.01^{\mathrm{c} 3}$ & $2.22 \pm 0.01^{\mathrm{d} 3}$ & $1.62 \pm 0.01^{\mathrm{e} 3}$ \\
\hline 800 & $3.53 \pm 0.09^{\mathrm{al}}$ & $2.81 \pm 0.01^{\mathrm{b} 4}$ & $2.59 \pm 0.03^{c 4}$ & $1.86 \pm 0.02^{\mathrm{d} 4}$ & $1.38 \pm 0.02^{\mathrm{e} 4}$ \\
\hline
\end{tabular}

Mean values with different numbers as superscripts in a column are significant $(\mathrm{p} \leq 0.05)$. Mean values with different alphabets as superscripts in a row are significant $(\mathrm{p}$ $\leq 0.05)$. 
In human study, it has been shown that green tea helps to reduce obesity when consumed on daily basis. Antiobesity effect of green tea has been associated with its content of caffeine and catechins particularly (-)epigallocatechin-3-gallate (EGCG) (Al-Salafe et al., 2014). Their findings showed a reduction in body weight and visceral fat after the period of experimentation. In another study, the consumption of two servings of an extra highcatechin green tea led to improvements in body composition and reduced abdominal fatness in moderately overweight Chinese subjects (Wang et al., 2010). The result of the present study is in support of an earlier study that reported that the body weights of rats and their cholesterol, low-density lipoprotein cholesterol and plasma triglyceride were significantly reduced by feedings of green tea leaves to the rats (Lin and Lin-Shiau, 2006). Wickelgren (1998) also associated this to presence of caffeine in black tea which decrease food intake and increased thermogenesis and that the thermogenic effect induced the body weight reduction. Cao et al. (2004) further noted that the thermogenesis by caffeine was synergistically enhanced with catechins in rat adipose tissue. Dulloo et al. (2000) opined that caffeine ingestion elevated the metabolic rate and fat oxidation in vivo through lipolysis in fat cells and release of catecholamine. Bose et al. (2008) reported that mice fed diets supplemented with Lipton tea extract had significantly decreased food intake and subsequently decreased body weight and fat mass. Dulloo et al. (2000) added that serum leptin levels were also lowered in mice fed with diet supplemented with Lipton tea and decreased their appetite for food which in turn had significant reductive effect on their final weight gain as compared to the control. Ikeda et al. (1992) gave credit to this when he reported that a diet containing Lipton tea catechins at $0.2 \%$ showed a weight reductive action in mice at 27 weeks of feeding. On the other hand, Bailey and Day (1989) noted that Lipton tea reduced body weight gain in normal Thai subjects by increasing energy expenditure and fat oxidation. Wang et al. (2006) also suggested that catechin, polyphenols and caffeine which were present in Lipton tea may be effective promoters of thermogenesis and fat oxidation, resulting in reduction in body weight gain in Caucasians, Chinese and Japanese.

The result of this study further revealed that the LTAE caused significant decrease in fasting blood sugar for all the treated groups as compared to the control. This could be due to the presence of the phytochemicals such as flavonoids which have been suggested to directly improve the beta-cells of the pancreas (Mita et al., 1985). It could also be due to the presence of caffeine, which has been suggested to cause reduction in food intake due to loss of appetite (Harbowy et al., 1997). As a consequence, the liver could not metabolize any dietary glucose and this in turn led to decrease in fasting blood sugar. From the study of Anderson and Polansky (2002), fasting blood sugar reductive effect of Lipton tea may be due to their increase insulin stimulatory effect on the $\beta$-cells of the pancreas. Cameron et al. (2008) added that it might be due to inhibition of renal glucose reabsorption. Baynes and Thorpe (1999) purported that it is due to increase stimulation of glucose uptake by peripheral tissues and inhibition of intestinal glucose absorption, while Ikeda (1992) connected it to the inhibition of endogenous glucose production. Furthermore, Lipton tea fasting blood sugar lowering effect can be attributed to the presence of polyphenolic compounds which have been suggested to have hypoglycaemic effect (Hasanein et al., 2012). The hypoglycaemic effect of the polyphenols found in Lipton tea are mainly attributed to reduce intestinal absorption of dietary carbohydrate, modulation of the enzymes involved in glucose metabolism, modulation of intracellular signalling pathways and gene expression and increase glucose uptake in insulin-sensitive tissues (Mita et al., 1985). One of the most well-known properties of these polyphenols found in Lipton tea on carbohydrate metabolism is inhibition of $\alpha$-glucosidase and $\alpha$-amylase, the key enzymes responsible for digestion of dietary carbohydrate to glucose (Khan and Mukhtar, 2007). Lipton tea polyphenols including the theaflavin, therubigen, flavonoids and catechins could interfere with absorption of glucose from intestine through inhibition of sodiumdependent glucose transporters (SGLT), such as SGLT1 and SGLT2 (Leung et al., 2001). Lipton tea polyphenols are able to regulate the key pathway of carbohydrate metabolism and hepatic glucose homeostasis. These polyphenols as contained in Lipton tea have been reported to attenuate hepatic glucose output through downregulation and up-regulation of phosphoenolpyruvatecarboxykinase (PEPCK) (Li et al., 2013). In an in vitro study, epigallocatechins gallate (EGCG), one of the most abundant catechins in Lipton tea could activate adenosine monophosphate-activated protein kinase (AMPK) as a required pathway for the inhibition of gluconeogenic enzymes expression (Murray et al., 2014). AMPK, an important sensor of cellular energy status has a key role in metabolic control, it is the key cellular energy sensor that regulate glucose metabolism and is the main drug target of hypoglycaemic drugs such as metformin (Nelson et al., 2008). Activation of AMPK leads to increased glucose uptake via up-regulation of glucose transporters, turning off anabolic pathways such as gluconeogenesis and increase catabolic pathways in cells (Nelson et al., 2008).

The result of this research also revealed that the LTAE caused significant decrease in total cholesterol, triglycerides, low density lipoprotein cholesterol and very low density lipoprotein cholesterol, while there was an increase in high density lipoprotein cholesterol. This could also be attributed to the reduction in feed intake due to loss of appetite noticed within the period of experimentation. The reduction in feed intake might have reduced the amount of dietary source of lipids metabolized by the liver. And as a consequent effect it precipitated to the general decrease in the cholesterol level. The present study is in agreement with Atiku and Ubon (2011) that reported a decrease in total cholesterol, triglycerides, low density lipoprotein cholesterol and very low density lipoprotein cholesterol of rats, while there was an increase in high density lipoprotein cholesterol of the rats after the period of their experimentation. This can be attributed to the suppression of intestinal absorption of lipids by the Lipton tea polyphenols and increase in the 
100

excretion of fats (Dulloo et al., 2000). These polyphenols as contained in Lipton tea affect lipid metabolism by different pathways and prevent the appearance of atherosclerotic plaque which is a precursor to other cardiovascular diseases (Khan et al., 2014). These polyphenols also has an inhibitory effect on acetyl-coA carboxylase which is essential for fatty acid biosynthesis in vitro (Prasad et al., 2009). Several mechanisms have been proposed for the lipidemic lowering effect of the polyphenols as contained in Lipton tea. The two main potential mechanisms are decreased hepatic fatty acid synthase (FAS) and increased adenosine monophosphate-activated protein kinase (AMPK) activity (Maritim et al., 2003). AMPK is also a key cellular energy sensor that regulate lipid metabolism and hence is the main drug target of lipid lowering drugs such as statins (Nelson et al., 2008). Activation of AMPK leads to turning off anabolic pathways which include decreased fatty acid synthase for lipid synthesis and increased catabolic pathways in cells (Nelson et al., 2008).

The result of this study showed a significant decrease in the atherogenic index and the coronary risk index of the treated group in both time-dependent and dose dependent manner when compared to the control. The decrease in atherogenic index can be attributed to decrease in low density lipoprotein cholesterol (bad cholesterol) and increase in high density lipoprotein cholesterol (good cholesterol) while the lowering of coronary risk index is due to decrease in total cholesterol and increase in high density lipoprotein cholesterol (Adeneye and Olagunju, 2009). The Atherogenic index is the tendency of developing atherosclerosis which is normally a precursor of cardiovascular diseases while coronary risk index is the tendency of developing heart related diseases like myocardial infarction, hypertension, high blood pressure etc. The finding of this study is in agreement with the results of Hasanein et al. (2012). Their finding showed a decrease in both atherogenic index and coronary risk index. He also opined that the decrease in atherogenic index can be attributed to decrease in low density lipoprotein cholesterol and increase in high density lipoprotein cholesterol while the lowering of coronary risk index is due to decrease in total cholesterol and increase in high density lipoprotein cholesterol.

\section{Conclusions}

Since the doses of Lipton tea extract used in this study significantly decreased the body weight gain of the normal male albino rats, reduced the fasting blood sugar, lowered the total cholesterol, triglycerides, low density lipoprotein cholesterol, very low density lipoprotein cholesterol, atherogenic index and coronary risk index, but increased the high density lipoprotein cholesterol, it is therefore concluded that Lipton tea extract possesses great potential for anti-obesity, hypoglycaemic and hypolipidemic properties. We recommend that further investigations should be made on this extract towards possible development of cheaper and safer alternatives to antidiabetic chemotherapy.

\section{References}

Abe K, Ijiri M, Suzuki T, Taguchi K, Koyama Y, Isemura M (2005). Green tea with high catechin content suppresses inflammatory cytokine expression in the galactosamine-injured rat liver. Biomedical Research 26(5):187-192.

Adeneye AA, Olagunju JA (2009). Preliminary hypoglycemic and hypolipidemic activities of the aqueous seed extract of Carica papaya Linn in Wistar rats. Biology and Medicine 1(1):1-10.

Ahmad N, Feyes DK, Agarwal R, Mukhtar H, Nieminen AL (1997). Green tea constituent epigallocatechin-3-gallate and induction of apoptosis and cell cycle arrest in human carcinoma cells. Journal of the National Cancer Institute 89(24):1881-1886.

Ahmed RG (2005). The physiological and biochemical effects of diabetes on the balance between oxidative stress and antioxidant defense system. Medical Journal of Islamic World Academy ofSciences 15(1):31-42.

Aizaki T, Osaka M, Hideyuki HA, Kurokawa S, Matsuyama K, ... Izumi T (1999). Hypokalemia with syncope caused by habitual drinking of oolong tea. Internal Medicine 38(3):252-256.

Al Jamal A (2014). Effect of rosemary (Rosmarinus officinalis) on lipid profiles and blood glucose in human diabetic patients (type-2). African Journal of Biochemistry Research 8(8):147-150.

Allain CC, Poon LS, Chan CS, Richmond WF, Fu PC (1974). Enzymatic determination of total serum cholesterol. Clinical Chemistry 20(4):470475.

Al-Salafe R, Irshad M, Abdulghani HM(2014). Does green tea help to fight against obesity? An overview of the epidemiological reports. Austin Journal ofClinical Medicine 1(3):1011.

Anderson RA, Polansky MM (2002). Tea enhances insulin activity. Journal of Agricultural and Food Chemistry 50(24):7182-7186.

APA (2012). Guidelines for ethical conduct in the care and use of nonhuman animals in research. USA, Washington DC: American Psychological Association. Retrieved June 13, 2015.

Atiku MK, Ubon GA (2011). Studies on the hypoglycaemic, hypocholesterolaemic and acute toxicity of aqueous Gymnema sylvestre leafextract in rats. Bio-Research 9(1):738-742.

Bailey CJ, Day C (1989). Traditional plant medicines as treatments for diabetes. Diabetes Care 12(8):553-564.

Baynes JW, Thorpe SR (1999). Role of oxidative stress in diabetic complications: a new perspective on an old paradigm. Diabetes 48:1-9.

Bose M, Lambert JD, Ju J, Reuhl KR, Shapses SA, Yang CS (2008). The major green tea polyphenol, (-) -epigallocatechin-3-gallate, inhibits obesity, metabolic syndrome, and fatty liver disease in high-fat-fed mice. The Journal of Nutrition 38(9):1677-1683.

Broadhurst CL, Polansky MM, Anderson RA (2000). Insulin-like biological activity of culinary and medicinal plant aqueous extracts in vitro. Journal of Agricultural andFood Chemistry 48(3):849-852.

Cameron AR, Anton S, Melville L, Houston NP, Dayal S, ... Rena G (2008). Black tea polyphenols mimic insulin/insulin-like growth factor-1 signalling to the longevity factor FOXO1a. Aging Cell 7:69-77.

Cao J, Luo SF, Liu JW, Li Y (2004). Safety evaluation on fluoride content in black tea. Food Chemistry 88(2):233-236. 
Dulloo AG, Seydoux J, Girardier L, Chantre P, Vandermander J (2000). Green tea and thermogenesis: interactions between catechinpolyphenols, caffeine and sympathetic activity. International Journal of Obesity 24(2):252-258.

Duncan DB (1955). Multiple range and multiple F tests. Biometrics 11(1):1-42.

Eyo JE, Ozougwu JC, Echi PC (2011). Hypogycaemic effects of Allium cepa, Allium sativum and Zingiber officinale aqueous extracts on alloxaninduced diabetic Rattusnovergicus. Medical Journal of the Islamic World Academic Sciences 19(3):121-126.

Ezuruike UF, Prieto JM (2014). The use of plants in the traditional management of diabetes in Nigeria: Pharmacological and toxicological considerations. Journal of Ethnopharmacology 155(2):857-924.

Finley PR, Schifman RB, Williams RJ, Lichti DA (1978). Cholesterol in high-density lipoprotein: use of $\mathrm{Mg}^{2+} /$ dextran sulfate in its enzymic measurement. Clinical Chemistry 24(6):931-933.

Fossati P, Prencipe L (1982). Serum triglycerides determined colorimetrically with an enzyme that produces hydrogen peroxide. Clinical Chemistry 28(10):2077-2080.

Friedwald WT, Leve RI, Fredrichson DS (1972). Estimation of concentration of low density lipoproteins separated by three different methods. Clinical Chemistry 18(6):499-502.

Harbowy ME, Balentine DA, Davies AP, Cai Y (1997). Tea chemistry. Critical Reviews in Plant Science 16(5):415-480.

Hasanein MA, Gawad HS, El-Megeid AA (2012). Effect of water extract prepared from green tea, black tea and cinnamon on obese rats suffering from diabetes. World Applied Sciences Journal 20(7):976-987.

Ikeda I, Imasato Y, Sasaki E, Nakayama M, Nagao H, ... Sugano M (1992). Tea catechins decrease micellar solubility and intestinal absorption of cholesterol in rats. Biochimica et Biophysica Acta (BBA)-Lipids and Lipid Metabolism 1127(2):141-146.

Khan M, Ali M, Ali A, Mir SR (2014). Hypogycemic and hypolipidemic activities of Arabic and Indian origin Salvadora persica root extract on diabetic rats with histopathology of their pancreas. International Journal ofHealth Sciences 8(1):45-56.

Khan N, Mukhtar H (2007). Tea polyphenols for health promotion. Life Sciences 81(7):519-533.

Khan N, Mukhtar H (2013). Tea and health: studies in humans. Current Pharmaceutical Design 19(34):6141-6147.

King H, Aubert RE, Herman WH (1998). Global burden of diabetes, 1995-2025: prevalence, numerical estimates, and projections. Diabetes Care 21(9):14141431.

Leung LK, Su Y, Chen R, Zhang Z, Huang Y, Chen ZY (2001). Theaflavins in black tea and catechins in green tea are equally effective antioxidants. The Journal of Nutrition 131(9):2248-2251.

Li S, Lo CY, Pan MH, Lai CS, Ho CT (2013). Black tea: chemical analysis and stability. Food and Function 4(1):10-18.

Lin JK, Lin-Shiau SY (2006). Mechanisms of hypolipidemic and antiobesity effects of tea and tea polyphenols. Molecular Nutrition and Food Research 50(2):211-217.
Maritim AC, Sanders A, Watkins JB (2003). Diabetes, oxidative stress, and antioxidants: a review. Journal of Biochemical and Molecular Toxicology 17(1):24-38.

Mita M, Borland K, Price JM, Hall PF (1985). The influence of insulin and insulin-like growth factor-I on hexose transport by Sertoli cells. Endocrinology 116(3):987-992.

Murray RK, Granner DK, Mayes PA, Rodwell VW (2014). Harper's illustrated biochemistry. USA: McGraw-Hill.

Nelson DL, Lehninger AL, Cox MM (2008).Lehninger principles of biochemistry. Macmillan.

Ozougwu JC, Eyo JE (2010). Studies on the anti-diabetic activity of Allium sativum (garlic) aqueous extracts on alloxan-induced diabetic albino rat. Pharmacologyonline 2010(2):1079-1088.

Ozougwu JC, Eyo JE (2011). Evaluation of the activity of Zingiber officinale (ginger) aqueous extracts on alloxan-induced diabetic rats. Pharmacologyonline 2011(1):258-269.

Ozougwu JC, Nwachi UE, Eyo JE (2008). Comparative hypolipidaemic effects of Allium cepa, Allium sativum and Zingiber officinale aqueous extracts on alloxan-induced diabetic Rattus novergicus. Bio-Research 6(2):384-391.

Parasuraman S, Raveendran R, Kesavan R (2010). Blood sample collection in small laboratory animals. Journal of Pharmacology and Pharmacotherapeutics 1(2):87-93.

Prasad SK, Kulshreshtha A, Qureshi TN (2009). Antidiabetic activity of some herbal plants in streptozotocin induced diabetic albino rats. Pakistan Journal of Nutrition 8(5):551-557.

Richmond N (1973). Colorimetric determination of total cholesterol and high density lipoprotein cholesterol (HDL-c). Clinical Chemistry 19:1350-1356.

Trinder P (1969). Determination of blood glucose using an oxidaseperoxidase system with a non-carcinogenic chromogen. Journal of Clinical Pathology 22(2):158-161.

Wang H, Wen Y, Du Y, Yan X, Guo H, Rycroft JA, ... Mela DJ 2010). Effects of catechin enriched green tea on body composition. Obesity 18(4):773-779.

Wang S, Noh SK, Koo SI (2006). Epigallocatechin gallate and caffeine differentially inhibit the intestinal absorption of cholesterol and fat in ovariectomized rats. Journal of Nutrition 136(11):2791-2796.

Wickelgren I (1998). Obesity: How big a problem? Science 280(5368):1364-1367.

Willett W, Manson J, Liu S (2002). Glycemic index, gycemic load, and risk of type 2 diabetes. American Journal of Clinical Nutrition 76(1):274S$280 \mathrm{~S}$.

Yashin A, Yashin Y, Nemzer B (2013). Beneficial effect of tea on human health. American Journal of Biomedical Sciences 5(4):226-241. 